\title{
EL CONCEPTO DE DERECHO Y EL ARGUMENTO DE LA RELEVANCIA PRÁCTICA ${ }^{1}$
}

\author{
José Manuel Cabra Apalategui \\ Universidad de Málaga
}

\begin{abstract}
RESUMEN. Este artículo analiza la corrección de algunos argumentos que han sido utilizados para apoyar o criticar un cierto concepto de Derecho. Su principal tesis es la siguiente: ni existe una conexión analítica, y por tanto necesaria, entre Derecho y moral, ni hay razones relacionadas con consecuencias prácticas para preferir, desde un punto de vista normativo, un concepto positivista de Derecho a uno no positivista, o viceversa. Respecto a la primera parte de la tesis (la conexión necesaria), se discuten argumentos como el de la pretensión de corrección de nuestros actos de habla normativos o la pretensión de legitimidad de la regla de reconocimiento. La segunda parte de la tesis (el punto de vista normativo) se basa en el argumento de que tanto positivistas como no positivistas se equivocan cuando los primeros sostienen que un concepto de Derecho no positivista favorece una legitimidad no crítica de los ordenamientos jurídicos, y también cuando, por el contrario, el concepto de Derecho no positivista se fundamenta en la idea de su mayor efectividad para evitar injusticias en los ordenamientos jurídicos.
\end{abstract}

Abstract. This paper analyzes the soundness of a number of arguments that have been put forward to either support or oppose a certain concept of law. Its main thesis goes as follows: there is no analytic, and therefore necessary, connection between law and morality, nor are there reasons related to their practical consequences when preferring a positivist concept of law to a non positivist one, or vice versa, from a normative point of view. With reference to the first part of the thesis (necessary connection), arguments such as the claim of correctness of our normative speech acts, or the claim of legitimacy of the rule of recognition are contested. The second part of the thesis (the normative point of view) is based on the argument that both positivism and non-positivism, are incorrect when the former maintains that a non-positivist concept of law favours a non critical legitimacy of legal orders, and also when, in contrast, such a concept of law is supported by the idea of a greater effectiveness in order to avoid injustice in legal orders.

${ }^{1}$ Este trabajo fue presentado como comunicación a las XX Jornadas de la Sociedad Española de Filosofía Jurídica y Política, celebradas en Málaga el 11 y 12 de marzo de 2005. 


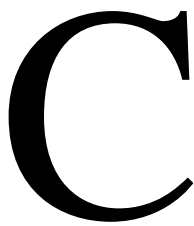

omo pone de manifiesto la perplejidad inicial de Hart en The Concept of Law, la del concepto de Derecho sigue siendo la cuestión central de la Teoría del Derecho. No creo necesario detenernos en esto. Sin embargo, resulta dudoso que siempre se haya abordado de un modo acertado.

El debate acerca de qué sea el Derecho se desarrolla en planos distintos: analítico, normativo y empírico, pero sólo en los dos primeros gira la discusión acerca del concepto de Derecho (dimensión intensional). Qué sea y qué no Derecho, esto es, la extensión del concepto, es algo distinto y lógicamente posterior; se trata de una cuestión empírica que presupone la cuestión conceptual: los casos son necesariamente posteriores al género. El debate genuinamente conceptual es, por tanto, otro.

En el plano analítico, la discusión gira en torno a si nuestros usos lingüísticos presuponen ya algún tipo de propiedad consustancial al concepto de Derecho; algo así como si pudiéramos encontrar en el lenguaje la clave para resolver el problema del concepto del Derecho. En el plano normativo, en cambio, la cuestión se plantea como una definición, como una estipulación lingüística y, por tanto, arbitraria, aunque en modo alguno trivial. Aquí se discuten las razones por las que un concepto de Derecho resultaría preferible a los conceptos alternativos; estas razones pueden ser de tipo epistémico o de tipo práctico.

Por muy compleja y aparentemente novedosa que pueda ser, toda discusión en torno al concepto de Derecho deviene en una discusión acerca de la relación entre el Derecho y la Moral. Tanto en el plano analítico, como en el normativo, el debate ha sido reducido tradicionalmente a dos posturas aparentemente irreductibles: por un lado, la representada por el positivismo jurídico, condensada en la denominada tesis de la separación, y, por otro, la tesis de la vinculación, bajo la que caen los planteamientos no positivistas. Pero, como han advertido algunos autores ${ }^{2}$, cuál sea el contenido de estas tesis dista mucho de ser claro y unívocamente entendido. De ser así, nos encontraríamos en una situación parecida a aquélla en que el debate acerca del concepto de Derecho giraba en torno a la distinción entre "positivismo" e "iusnaturalismo", sin advertir, como más tarde hicieron, entre otros, Hart

\footnotetext{
${ }^{2}$ Véase, Füßer, K. "Farewell to Legal Positivism: The Separation Thesis Unravelling”, en George, R. P. (ed.) The Autonomy of Law. Essays on Legal Positivism, Oxford University Press, Oxford, 1996, págs. 119-162; Juan Carlos Bayón, "El contenido mínimo del positivismo jurídico”, en Zapatero, V. (ed.), Horizontes de la Filosofía del Derecho. Homenaje a Luis García San Miguel, Universidad de Alcalá, 2002 (2 Vols.), Vol. II, págs. 31-54; Navarro, P. E. “Tensiones conceptuales en el positivismo jurídico”, DOXA 24 (2001), págs. 133-163.
} 
y Bobbio, que bajo esas etiquetas caían distintas tesis conceptualmente independientes, de manera que la adhesión a una de ellas no implicaba necesariamente el compromiso con las demás. De hecho, la mayor parte, si no la totalidad, de autores a los que se calificaba como positivistas consideraban indefendibles muchas de las tesis que sus detractores, partiendo de construcciones cuando menos toscas y poco elaboradas del positivismo jurídico, les atribuían. Evitar los debates estériles e improductivos, así como acuerdos y desacuerdos sólo aparentes, pasa por definir previamente con tanta claridad como sea posible qué es lo que se discute. Cuanto más nos acerquemos a este objetivo, más racional será la discusión.

En este trabajo voy a sostener dos tesis: (i) no podemos establecer en el plano analítico ningún tipo de conexión necesaria entre Derecho y Moral; y (ii) desde un punto de vista normativo, no hay razones para preferir uno $\mathrm{u}$ otro concepto de Derecho en relación con sus consecuencias prácticas.

\section{II}

La supuesta existencia de una conexión necesaria, ineludible, entre Derecho y Moral es, naturalmente, una cuestión conceptual. Ahora bien, con la expresión "conexión necesaria” se puede estar haciendo referencia a dos tesis distintas, según el sentido que se atribuya al término "necesidad”3. En primer lugar, se trata de una necesidad de tipo analítico. En este caso, lo que se estaría afirmando es que las reglas que rigen nuestros usos lingüísticos, y en especial aquellas que constituyen el núcleo de significado de nuestros actos de habla regulativos, de los que legislar o juzgar son casos específicos, presuponen ya dicha conexión. Este sentido coincide con la que se denomina como tesis de la pretensión de corrección, según la cual nuestros actos de habla regulativos formulan una pretensión de corrección o legitimidad. Ésta incorpora, a su vez, una pretensión de fundamentabilidad, es decir, que quien formula la pretensión de corrección está afirmando implícitamente la existencia de razones, entre ellas razones morales, para seguir lo prescrito en el acto regulativo correspondiente. En segundo lugar, se puede hacer referencia a una necesidad de tipo empírico. En este caso, la afirmación de que entre el Derecho y la Moral existe una conexión necesaria significa que la existencia de los ordenamientos jurídicos depende de que su regla de reconocimiento formule una pretensión de corrección, y que es imposible lo contrario; en otras palabras, que constituye una condición de posibilidad de la existencia de un ordenamiento jurídico. Aquí pretendo cuestionar ambas versiones de la tesis de la conexión necesaria.

\footnotetext{
${ }^{3}$ Aquí me voy a referir únicamente a las tesis que pueden ser formulas considerando la ambigüedad del término "necesidad” y no al de “conexión”.
} 
(i) La versión analítica de la tesis de la conexión necesaria suele adoptar como punto de partida algunos ejemplos célebres formulados por los filósofos del lenguaje que muestran las implicaciones presupuestas en nuestros usos lingüísticos. Así, la afirmación de Wittgenstein:

"Si hubiera un verbo con el significado "creer falsamente”, no tendría sentido usarlo en la primera persona del presente del indicativo [...] "creo ..., y no es así” sería una contradicción”4.

O la de Austin:

"El gato está sobre el felpudo, pero yo no lo creo"s.

En ambos casos se pretende mostrar que quien afirma creer algo formula una pretensión de verdad acerca de su creencia, de manera que no puede afirmar que lo que cree no es verdad. No resulta comprensible sostener la verdad de una creencia y admitir seguidamente que se carece de razones para ello, o peor aún, que se tienen buenas razones para creer lo contrario. No obstante, nótese que ambos ejemplos giran en torno a una cuestión empírica: tener una creencia, y se trata, por tanto, de un uso descriptivo del lenguaje.

Algunos autores han visto en la extrapolación de estos ejemplos al terreno práctico, un buen argumento, o al menos su comienzo, para sostener la tesis de la conexión necesaria. Garzón Valdés, por ejemplo, sostiene que resultarían contradictorias afirmaciones del tipo:

"Creo en la legitimidad de mi sistema pero es ilegítimo / Creo en la legitimidad de mi sistema pero no pretendo que lo sea / Creo que la regla de reconocimiento coincide con mis valoraciones primarias pero es incorrecta moralmente / Mi posición moral es éticamente incorrecta" ${ }^{6}$.

Con ello se pretende mostrar que el participante ${ }^{7}$ (legisladores, jueces, etc.) en un sistema jurídico formula siempre una pretensión de legitimidad o corrección y, con ello, que, al menos desde el punto de vista del participante, existe una conexión necesaria entre Derecho y Moral.

En efecto, los anteriores enunciados son todos, de un modo más o menos evidentes, contradictorios, faltos de sentido al igual que los ejemplos de

\footnotetext{
${ }^{4}$ Wittgenstein, L. Investigaciones filosóficas (trad. A. García Suárez y U. Moulines), UNAM / Crítica, México / Barcelona, 1988, pág. 439.

${ }^{5}$ Austin, J. L. Cómo hacer cosas con palabras (trad. G. Carrió y E. Rabossi), Paidós, 1971, págs. 91 y ss.; “El significado de una palabra”, en Id. Ensayos filosóficos (trad. A. García Suárez), Alianza, Madrid, 1989, págs. 71-87, cita en pág. 77.

${ }^{6}$ Garzón Valdés, E. “Algo más acerca de la relación entre Derecho y Moral”, en Id. Derecho, Ética y Política, CEC, Madrid, 1993, págs. 317-335, cita en pág. 327.

${ }^{7}$ Aquí voy a dejar de un lado la cuestión, poco clara todavía de qué signifique adoptar el punto de vista del participante; sobre esta cuestión, véase el artículo de Liborio Hierro “¿Por qué ser positivista?”, en DOXA 25 (2002), págs. 263-302, en especial págs. 263-279.
} 
Wittgenstein y Austin, pero, precisamente iporque son idénticos! En todos ellos se afirma y se niega simultáneamente por parte de una misma persona una misma creencia. Aquí resulta irrelevante que esta creencia se refiera a un estado de cosas o a valores morales, lo que importa es la creencia como hecho que se afirma y se niega. Ahora bien, este tipo de afirmaciones no muestra más que el hecho de que incurre en contradicción quien sostiene simultáneamente que una cosa es el caso y que no lo es. Podría decirse que ni siquiera plantean una auténtica pretensión de legitimidad o de corrección, sino que plantean, más bien, y en cuanto describen estados mentales de quien las formula, pretensiones de verdad. Estos enunciados abogarían, en todo caso, en favor del postulado de la consistencia lógica, pero no constituirían en ningún caso algo así como un principio de prueba de la tesis de la conexión necesaria. Esta tarea requeriría algo más.

Ese algo más podemos encontrarlo en el planteamiento de Robert Alexy. El autor alemán pretende mostrar que la pretensión de corrección es un elemento necesario del concepto de Derecho y cómo a través de ella puede establecerse una conexión necesaria entre Derecho y Moral. Para ello recurre al siguiente ejemplo: un Estado $X$ incluye como primer artículo de su texto constitucional lo siguiente:

" $X$ es una república soberana, federal e injusta”.

Según Alexy, este artículo es manifiestamente defectuoso, pero no sólo desde un punto de vista técnico o instrumental, moral o convencional, sino también, y esencialmente, conceptual. Ciertamente, la cláusula de la injusticia puede resultar políticamente inadecuada o disfuncional en el sentido de disminuir las probabilidades de efectividad de la Constitución, pero, el mismo defecto podría predicarse de una cláusula republicana que derogara una monarquía fuertemente arraigada y, en cambio, -sostiene Alexy- la primera cláusula (injusticia) tiene algo de absurdo, de lo que la segunda (republicana) carece. Igualmente, el contenido del artículo constitucional del ejemplo se aparta de la convención acerca de la redacción de textos constitucionales; y también lo haría la inclusión de un catálogo de derechos de cien páginas, sin embargo, a pesar de lo inusual, no se vería afectado por el sinsentido que supone la cláusula de la injusticia. Por último, también desde el punto de vista moral, esta cláusula es claramente defectuosa, ahora bien, aunque desde el punto de vista moral las cosas no serían muy distintas si ésta fuera suprimida y se incorporasen a la constitución otros artículos de contenido manifiestamente injusto, una y otra situación, equiparables en su injusticia,

${ }^{8}$ Alexy, R. "El concepto y la validez del Derecho", en Id. El concepto y la validez del Derecho (trad. J. M. Seña), Gedisa, Barcelona, 1997, págs, 13-130, cita en pág. 42. 
son, “desde el punto de vista de lo defectuoso”, diferentes en algún sentido. Lo absurdo de la cláusula de la injusticia no se explica, por tanto, únicamente sobre la base de razones técnicas, convencionales o morales, sino también por razones conceptuales. Según Alexy, un artículo como este es conceptualmente defectuoso porque

"[c]on el acto de la sanción de una Constitución está vinculada necesariamente la pretensión de corrección que, en este caso, es, sobre todo, una pretensión de justicia”.

En otras palabras, el defecto consiste en que lo que está explícitamente manifestado en el acto de habla contradice lo que está implícitamente presupuesto en el mismo. A esto se denomina contradicción performativa. Y, por la misma razón por la que la cláusula de la injusticia resulta contradictoria, un artículo como:

“ $X$ es un Estado justo" 10

sería un enunciado redundante.

Obviamente, la clave de la cuestión está en el presupuesto de la pretensión de corrección. Con ello, Alexy introduce el elemento que hace que funcione la tesis de la conexión necesaria, pero sólo de un modo aparente o tramposo. Dos comentarios al respecto: en primer lugar, el argumento de la contradicción performativa sólo funciona si ya se presupone lo que se pretende mostrar: el carácter necesario de la pretensión de corrección o legitimidad; sólo así podemos decir que la cláusula de la injusticia contradice los presupuestos de los “actos de habla constituyentes”, por llamarlos de algún modo. En segundo lugar, sostener que un presupuesto como ese rige este tipo de actos es algo más que discutible. Pensemos en un texto de un preámbulo constitucional del siguiente tenor:

" $Z$ es una república cuyo fin supremo es la salvaguarda del interés de los grupos étnicos mayoritarios y, en todo caso, de los ciudadanos del Estado frente a cualesquiera otras personas, así como favorecer los medios necesarios para la estabilidad política, aunque ello suponga renunciar a las convicciones morales e ideales de justicia mayoritarias"11.

La opción del constituyente es muy clara: privilegiar el interés de algunos grupos sociales y, en última instancia, de la ciudadanía frente a cualesquiera otros individuos, aunque ello suponga el sacrificio de los valores morales de la comunidad. Supongamos que se trata de un Estado de un

${ }^{9}$ Idem, pág. 43.

${ }^{10}$ Idem, pág. 43.

11 Véase un argumento similar en Engländer, A. “Zur begrifflichen Möglichkeit der Rechtspositivismus. Eine Kritik des Richtigkeitsargument von Robert Alexy”, Rechtstheorie 28 (1997), págs. 437-485, cita en pág. 444. 
gran potencial económico donde los intereses que la Constitución protege superan con mucho el umbral de lo que generalmente se entiende como necesidades básicas. Supongamos también que, preguntados por sus convicciones morales, la mayoría de los habitantes de ese Estado, pero, sobre todo, aquellos que representan el sector institucional (legisladores, jueces, etc.), reconocen que dichas necesidades constituyen un mínimo moral ineludible para cualquier persona, independientemente de su condición de ciudadano o no, y, sin embargo, una debilidad de la voluntad muy extendida les impide renunciar a los bienes e intereses que la Constitución protege para satisfacer las necesidades básicas de otras personas. Desde luego que no puede hablarse en este caso de una auténtica pretensión de corrección o legitimidad, pero ¿hay algún tipo de contradicción? Creo que no. Resulta altamente contraintuitivo sostener que el enunciado anterior es conceptualmente defectuoso; puede que sea inusual, inmoral o políticamente inapropiado, pero no alcanzo a ver dónde reside el defecto conceptual. Salvo que presuponga, como hace Alexy, que todo acto de sanción de una Constitución formula necesariamente una pretensión de corrección o legitimidad, no hay nada de contradictorio en el texto anterior. Si podemos hablar de algo así como la reconstrucción de las prácticas sociales en las que tomamos parte, y por esto entiendo algo distinto a una mera definición o estipulación, entonces cabría decir que la reconstrucción alexiana de lo que antes denominé como "acto de habla constituyente” tiene en la tesis de la pretensión de corrección o legitimidad un presupuesto discutible: no es que no sea deseable o habitual que se formule (lo cual no evita, en modo alguno, la incorrección moral de hecho de muchos sistemas jurídicos), simplemente, creo que es algo contingente. El desencuentro se produce, por tanto, en la identificación de las reglas que rigen la práctica constituyente: en mi opinión, el contenido mínimo del mismo se reduce a la mera intención de constitución en comunidad política, independientemente del fundamento que a la misma otorguen aquellos que la integran (la realización de una concepción compartida de la justicia, la salvaguarda del propio interés, etc.); Alexy y otros muchos, en cambio, sostendrían que la pretensión de corrección o legitimidad también formaría parte de ese contenido mínimo ${ }^{12}$. Con independencia de cuál nos parezca una mejor o más adecuada reconstrucción de las reglas que rigen la sanción de una Constitución, lo anterior pone de manifiesto que la versión analítica de la tesis de la conexión necesaria descansa en presuponer algo

\footnotetext{
12 Para una crítica del argumento de la corrección en un sentido distinto al aquí planteado, véase Bulygin, E. “Alexy und das Richtigkeitsargument”, en Aarnio, A / Paulson, S. / Weinberger, O. / von Wright, g. h. / Wyduckel, D. (Hsg.) Rechtsnorm und Rechtswirlichkeit. Festschrift für Werner Krawietz, Duncker \& Humblot, Berlin, 1993, págs. 19-24.
} 
que, desde un punto de vista distinto y, en mi opinión, no sólo no descabellado, sino, incluso, más adecuado, es contingente. De algún modo, Alexy ha visto en la convención o, mejor, en las prácticas más habituales, el núcleo de significado de las mismas. Creo, sin embargo, que la tarea de reconstruir objetivamente las prácticas sociales mediante la identificación de sus reglas es algo más complejo que la mera constatación de qué suele hacerse o cual es el contenido expresamente reconocido por todos o algunos de los participantes en las mismas ${ }^{13}$, pero esto es algo que excede los objetivos de este trabajo.

Desde posiciones muy similares a las de Alexy, MacCormick hace notar que hablamos de "administración de justicia” y no de "administración de injusticia” para referirnos a las instituciones que aplican el Derecho, así como a las prácticas que en ellas se desarrollan ${ }^{14}$. Pero que esto pueda considerarse un argumento favorable para la tesis de la pretensión de corrección es más que dudoso. Ciertamente, la denominación de "administración de justicia” formula una pretensión de legitimidad, pero ésta puede ser leída también, y exclusivamente si se quiere, en clave política: se trataría, entonces, una cuestión de eficacia política sustentada en el efecto retórico de los términos. Por otro lado, las instituciones a que nos referimos y, sobre todo, las prácticas que en ellas se llevan a cabo pueden ser, de hecho son, reconstruidas o consideradas sin recurrir a la pretensión de corrección o legitimidad con denominaciones como "instancias o mecanismos de resolución de conflictos”, propias de la sociología jurídica y asumibles por cualquier planteamiento crítico y/o mínimamente escéptico (por ejemplo, el de un abogado descreído).

(ii) Hasta aquí he intentado mostrar que la tesis de la conexión necesaria entre Derecho y Moral basada en la pretensión de corrección vinculada a determinadas prácticas o actos de habla regulativos incurre en una petición de principio. Ahora voy a cuestionar la versión empírica de la tesis de la conexión necesaria, según la cual la existencia de los ordenamientos jurídicos depende de que su regla de reconocimiento formule una pretensión de corrección o legitimidad.

\footnotetext{
${ }^{13}$ Creo que bajo esta afirmación late la distinción introducida por Bayón entre "convencionalismo superficial” y “convencionalismo profundo” en relación con la ontología de las convenciones sociales; véase Bayón, J. C. "El contenido mínimo del positivismo jurídico”, op. cit., en especial págs. 48 y ss.; y del mismo autor, "Derecho, convencionalismo y controversia”, en Navarro, P. E. / Redondo, M. C. (comp.) La relevancia del derecho. Ensayos de filosofía jurídica, moral y política, Gedisa, Barcelona, 2002, págs. 57-91, especial, págs. 76 y ss.

${ }^{14}$ MacCormick, N. "Natural Law and the separation of Law and Morals”, en George, P. Natural Law Theory, Oxford University Press, Oxford, 1992, págs. 105-133, cita en pág. 112.
} 
Este es el tipo de argumento que ha desarrollado, entre otros, Garzón Valdés, cuyo planteamiento sigo aquí. Según este autor:

“Todo sistema jurídico existente (...) requiere como condición necesaria, pero no suficiente, la adhesión a sus principios y normas por parte de las autoridades y funcionarios del sistema”" ${ }^{15}$.

Esta actitud es la que Hart denominó como "punto de vista interno". Adoptar el punto de vista interno del sistema jurídico supone aceptar sus normas como pautas de conducta. Aunque a primera vista no sea necesario recurrir a criterios de validez externos al propio sistema, la aceptación y aplicación de las normas que configuran el sistema se sustenta en última instancia en justificaciones morales ${ }^{16}$.

Pero, como el propio autor reconoce, se puede objetar que la actitud moral de la parte oficial del sistema nada tenga que ver con su estabilidad o existencia. Admite, entonces, dos situaciones en las que no concurre la adhesión de la parte oficial, que antes se concibió como condición necesaria de todo sistema jurídico. La primera de estas situaciones sería aquella en la que toda la parte oficial rechaza internamente el sistema, aunque se adhiere externamente por motivos prudenciales al creer erróneamente en la adhesión sincera del resto; se trataría de una situación de error generalizado. El segundo de los escenarios sería aquel en el que la parte oficial cumple las reglas por hábito, tradición o aburrimiento, sin manifestar una adhesión explícita a las reglas básicas del sistema; aquí se trata de una ausencia de reflexión generalizada. Estas situaciones son, obviamente, no sólo harto improbables, sino, también, muy poco duraderas ${ }^{17}$.

Es posible, sin embargo, pensar una tercera situación en la que la parte oficial del sistema (y no sólo ésta) se adhiere a las normas básicas del mismo no por razón de sus convicciones morales, sino para una maximización de utilidad. En otras palabras, el sistema no se configura como una unidad moral cuyos principios básicos definen en parte la regla de reconocimiento, sino como una mera comunidad de intereses basada en un compromiso igualmente ventajoso para todos, teniendo en cuenta las correlaciones de fuerza. Esto sería posible en un contexto en el que una gran cantidad de personas, entre ellos la parte oficial, antepusieran su interés a lo que consideran justo y fueran lo suficientemente sinceros como para admitir que lo hacen. En este caso, la validez de las normas del sistema no descansa en razones morales o en una pretensión de legitimidad o corrección, sino en una rela-

\footnotetext{
${ }^{15}$ Garzón Valdés, E. “Algo más acerca de la relación entre Derecho y Moral”, op. cit., pág. 320.

${ }^{16}$ Idem, pág. 321.

${ }^{17}$ Idem, pág. 324.
} 
ción de causalidad (empírica). Se trata, claro está, de una validez hipotética con base en el carácter instrumental de las normas: “debo comportarme de este modo si quiero alcanzar tal o cual fin (maximización del propio interés, realización de determinados valores de justicia, etc.)”. Aquí, en principio, no se plantean problemas de inestabilidad estructural. Este es el sentido de la siguiente afirmación de Hart:

“una condición necesaria para la existencia de un poder coactivo es que al menos algunos deben cooperar voluntariamente en el sistema y aceptar sus reglas [...] Puede que no sólo un gran número de personas sea obligado por leyes que no consideran moralmente vinculantes, es que ni siquiera es verdad que aquellos que aceptan el sistema voluntariamente, tengan que concebirse a sí mismos moralmente obligados a hacerlo, aunque el sistema será más estable si lo hacen. En realidad, su adhesión al sistema puede estar basada en muy diferentes consideraciones: cálculos de interés a largo plazo; falta de interés en los demás; y actitudes heredadas o tradicionales no reflexionadas; o el mero deseo de actuar como los demás. En verdad no hay razón por la cual aquellos que aceptan la autoridad del sistema no deberían examinar su conciencia y decidir que, moralmente, no deberían aceptarla, sin embargo, por diferentes razones, continúan haciéndolo"18.

Creo que Hart está en lo correcto al presuponer que todo sistema jurídico requiere de la adhesión o el compromiso de la parte oficial con sus normas básicas, pero no en un sentido de adhesión o compromiso moral. Personas no comprometidas moralmente, que aceptan el sistema por un cálculo de intereses, entre otros motivos posibles, son capaces de crear situaciones de estabilidad. El problema es, dice Garzón, si esta actitud puede ser generalizada:

"El concepto mismo de razones perentorias es dependiente de la atribución de autoridad a quien las formula, y quien se presenta como autoridad última del sistema no puede invocar -so pena de caer en un círculo vicioso- razones perentorias sino que tiene que adherir en sentido fuerte al contenido de sus normas, es decir, otorgarles su aprobación moral”"

Estas palabras ponen en claro algo que late en todo el planteamiento: la conexión entre autoridad y moralidad (legitimación y legitimidad). Esto conecta con el problema de las fuentes de la autoridad. La autoridad basada en los argumentos morales es un tipo de autoridad, el más racional y deseable si se quiere, pero no el único; la pretensión de legitimidad o corrección no es la única conexión posible entre el sistema jurídico y la autoridad. Esta

\footnotetext{
${ }^{18}$ Hart, H.L.A. The Concept of Law, Oxford University Press, Oxford, 1961, págs. 198-199 (subrayado mío).

${ }^{19}$ Garzón Valdés, E. “Algo más acerca de la relación entre Derecho y Moral”, op. cit., pág. 326.
} 
conexión depende de una tesis empírica: la tendencia generalizada de las personas hacia la corrección moral. Y, en tanto que tesis empírica, es contingente, no necesaria. Hay que hacer notar que el hecho de que en ocasiones se formulen pretensiones insinceras no refuta la tesis de la pretensión de legitimidad, puesto que se pretende, aunque sea a través del engaño, conectar la autoridad con la legitimidad. Lo que hace tambalearse a la tesis de la pretensión de corrección es la renuncia más o menos explícita y generalizada a las convicciones morales en favor de otros intereses o deseos. Si esto es posible, y creo que lo es, entonces, no hay una conexión necesaria entre Derecho y Moral en el sentido de que los sistemas jurídicos deban incorporar en su regla de reconocimiento una pretensión de corrección.

\section{III}

La argumentación en el plano analítico no resulta concluyente al intentar mostrar la validez de la tesis de la vinculación. La cuestión acerca del concepto de Derecho puede continuar, sin embargo, en el plano normativo, en términos de preferibilidad. No se trata aquí de que las cosas sean o no necesariamente de un modo u otro, sino de que la adopción de un concepto u otro de Derecho obedezca a razones, bien de tipo teórico, bien de tipo práctico. Aquí voy a sostener que no hay razones prácticas definitivas para preferir un concepto de Derecho a otro ${ }^{20}$.

Como es sabido, Gustav Radbruch, culpabilizó al positivismo jurídico de los males del derecho nacionalsocialista afirmando, entre otras cosas, que la doctrina positivista había dejado "indefensos" a los juristas alemanes. Gran parte de estas afirmaciones se basan en una representación muy poco sutil, casi caricaturesca, del positivismo jurídico. Con el tiempo, el "argumento de la indefensión" se ha mostrado, como hipótesis histórica, manifiestamente falso $^{21} \mathrm{y}$, desde un punto de vista teórico, inaceptable ${ }^{22}$. Pero lo cierto es que la idea generó un amplio debate acerca de si había o no razones morales (prácticas) para preferir uno u otro concepto de Derecho, esto es, acerca de

\footnotetext{
${ }^{20}$ Podemos hablar aquí de una situación de “empate” o "tablas”; vid. Alexy, R. "El concepto y la validez del Derecho”, op. cit., pág. 67; Dorado Porras, J. Iusnaturalismo y Positivismo jurídico, Dykinson, Madrid, 2004, pág. 87.

${ }^{21}$ Garzón Valdés, E., "Notas sobre la Filosofía del Derecho alemana actual” y "Derecho natural e ideología”, en Id., Derecho, Ética y Política, op. cit., págs. 235-264 y 145-156, respectivamente.

${ }^{22}$ Vid. García Amado, J. A., "Nazismo, Derecho y Filosofía del Derecho”, en Id., Escritos sobre Filosofía del Derecho, Ediciones Rosaristas, Santa Fé de Bogotá, 1997, págs. 233-266; Füßer, K. "Rechtspositivismus und "gesetzliches Unrecht. Zur Destruktion einer verbreiteten Legende”, ARSP 78 (1992), págs. 301-331; Dorado Porras, J. Iusnaturalismo y Positivismo jurídico, op. cit., págs. 94-109.
} 
las consecuencias moralmente valiosas que tendría la adopción de uno u otro concepto de Derecho. Aquí voy a ocuparme de dos de esos argumentos: el argumento de la pervivencia de la legitimación acrítica y el argumento de la efectividad para combatir la injusticia.

(i) En principio, el argumento de la legitimación acrítica del Derecho fue esgrimido por el iusnaturalismo contra el hecho de que el formalismo positivista, agravado por el escepticismo ético de muchos de los autores alineados con el positivismo, admitiera como norma jurídica cualquier norma producida por los procedimientos jurídicamente establecidos, con independencia de cuál fuera su contenido, incluso cuando éste era manifiestamente injusto. Sin embargo, el argumento iusnaturalista suponía cosas que los positivistas, o al menos la mayoría de ellos, no defendían: la existencia de una obligación absoluta de obediencia al Derecho válido y un total desinterés por las cuestiones morales. Este error, la identificación de todo positivismo con el más exótico de ellos, el positivismo ideológico extremo o fuerte, así como la presunción de una actitud de indiferencia moral respecto al Derecho, sustenta el argumento de la indefensión. Pero el argumento de la indefensión no sólo ha sido refutado con éxito por el positivismo, sino que le ha sido devuelto a los iusnaturalistas en forma de acusación: es la utilización del término Derecho tal y como propone el iusnaturalismo lo que propicia en mayor medida la legitimación acrítica del sistema jurídico. Como muestra, las ya clásicas palabras de Hart:

"Lo que por cierto más se necesita para que los hombres tengan una visión clara al enfrentar el abuso oficial de poder, es que conserven la idea de que al certificar que algo es jurídicamente válido no resolvemos en forma definitiva la cuestión de si se le debe obediencia, y que por grande que sea el halo de majestad o de autoridad que el sistema oficial pueda poseer, sus exigencias, en definitiva, tienen que ser sometidas a un examen moral. Esta idea de que fuera del sistema oficial hay algo que, en última instancia, deberá proporcionar al individuo el criterio para resolver sus problemas de obediencia, es más probable, por cierto, que permanezca viva entre quienes están acostumbrados a pensar que las reglas jurídicas pueden ser inicuas, que entre quienes piensan que en ningún caso algo inicuo puede tener status de derecho"23.

A este argumento cabe oponer, al menos, tres objeciones. En primer lugar, está basado en una relación causal discutible. Según este argumento, la adopción de un concepto de Derecho positivista por parte de la parte oficial de un sistema jurídico tiene como efecto la actitud de vigilancia crítica por parte de los ciudadanos (o si se quiere, una mayor probabilidad de que esto ocurra), pero, como ha puesto de manifiesto Garzón Valdés, “no cuesta en-

\footnotetext{
${ }^{23}$ Hart, H.L.A. The Concept of Law, op. cit., pág. 206.
} 
contrar contraejemplos históricos que permiten poner en duda la corrección de la tesis según la cual habría una relación causal entre jusnaturalismo y positivismo y el comportamiento ciudadano. En la larga lista de los cómplices de las dictaduras, se encuentran tanto jusnaturalistas como juspositivistas, y los períodos de vigencia de una y otra posición no coinciden con los resultados esperados o temidos por los filósofos del derecho" ${ }^{24}$. Una confianza excesiva e infundada en la capacidad de influencia de los conceptos de los teóricos del derecho en el comportamiento general de la población hace de éste (y también de su contrario) un argumento implausible.

El segundo problema a que se enfrenta el argumento de la legitimación acrítica es el de la incoherencia. Este argumento supone que la adopción por la parte oficial del sistema de un concepto iusnaturalista tendrá como consecuencia el reconocimiento automático y acrítico de los ciudadanos de todo derecho como derecho justo. Pero, como ha sugerido Bayón, este planteamiento encierra una paradoja. Antes que nada debemos notar que el núcleo de la tesis positivista de la separación es la llamada tesis de las fuentes sociales, según la cual la existencia y el contenido del Derecho dependen exclusivamente de hechos sociales más o menos complejos. Pues bien, el argumento de la legitimación acrítica del iusnaturalismo supone que, los ciudadanos, al tiempo que reconocen todo derecho como derecho justo sobre la base de un "uso iusnaturalista” del término "Derecho", tendrían que reconocer como Derecho todo aquello que emane del poder, lo cual sólo es posible adoptando un punto de vista iuspositivista. Es decir, el argumento previene, curiosa y contradictoriamente, acerca de las malas consecuencias que tendría la asunción generalizada de un concepto iusnaturalista de Derecho, pero supone, simultáneamente, que la gente sigue pensando en clave positivista (tesis de las fuentes sociales) ${ }^{25}$.

En tercer lugar, este argumento incurre en un error muy parecido a aquél del que fue víctima el positivismo de posguerra: la identificación de todo iusnaturalismo con su versión más extrema; aquella que hace depender la validez de todo Derecho de su adecuación a determinados estándares morales. Existen, sin embargo, propuestas iusnaturalistas (o no positivistas) que no establecen una conexión rígida entre la validez y el contenido de las normas, o más bien, que reducen sustancialmente dichos estándares. Un ejemplo de este tipo de planteamientos es el de Gustav Radbruch:

"El conflicto entre la justicia y la seguridad jurídica puede ser solucionado en el sentido de que el derecho positivo asegurado por su sanción y el poder

${ }^{24}$ Garzón Valdés, E. “Algo más acerca de la relación entre Derecho y Moral”, op. cit., pág. 333.

${ }^{25}$ Bayón, J. C. “El contenido mínimo del positivismo jurídico”, op. cit., pág. 38, nota. 13. 
tiene prioridad aun cuando su contenido sea injusto y disfuncional, a menos que la contradicción entre la ley positiva y la justicia alcance una medida tan insoportable que la ley, en tanto 'derecho injusto', tenga que ceder ante la justicia. Es imposible trazar una línea nítida entre los casos de injusticia legal y las leyes válidas a pesar de su contenido injusto; pero puede establecerse otra frontera con total precisión: donde ni siquiera se pretende la justicia, donde la igualdad, que constituye el núcleo de la justicia, es negada conscientemente en el establecimiento del Derecho positivo, ahí la ley no es sólo "Derecho injusto”, sino más bien carece totalmente de naturaleza jurídica”26.

Es posible distinguir, por tanto, tres situaciones distintas en las que se produce la inadecuación entre el derecho positivo y determinados estándares de justicia: el derecho injusto tolerable (en la que la justicia formal resiste el contraste con la justicia material), el derecho injusto intolerable (supuesto en el que la justicia formal cede frente a la justicia material) y el no derecho (carencia de naturaleza jurídica). Alexy, que asume enteramente las tesis de Radbruch, sostiene que éstas formulan una "tesis débil de la vinculación”27 que no exige un correlativo moral para toda norma jurídica, sino un marco de inmoralidad tolerable: el Derecho no es definido, sino limitado por la moral. Se trata, así, de una vinculación parcial entre derecho y moral ${ }^{28}$, de manera que seguiría siendo posible desde esta perspectiva una actitud crítica frente al Derecho ${ }^{29}$. El problema de este tipo de teorías tiene que ver más con el establecimiento de los límites entre las distintas situaciones de las que pretende dar cuenta (justificación de cierto grado de objetivismo moral) que el riesgo de legitimación acrítica del Derecho.

Resumiendo, el intento de justificar la preferibilidad de un concepto positivista de Derecho mediante el argumento de que un concepto iusnaturalista deriva necesariamente en la legitimidad acrítica del Derecho o que, al menos, el concepto positivista es más eficaz para evitar ese riesgo, no se sostiene.

(ii) Tampoco desde posiciones iusnaturalistas o no positivistas se ha renunciado a justificar la preferencia de la tesis de la vinculación (concepto de Derecho iusnaturalista) con argumentos morales, como el de la efectividad para combatir la injusticia.

La adopción de un concepto no positivista de Derecho como el de Radbruch puede tener una enorme trascendencia práctica, como se ha puesto

${ }^{26}$ Radbruch, G. “Gesetzliches Unrecht und übergesetzliches Recht”, en Id., Gesamtausgabe (Bd. 3), C.F. Müller, Heidelberg, 1990, pp. 83-93, cita en p. 89.

${ }^{27}$ Alexy, R. "El concepto y la validez del derecho”, op. cit., pág. 53.

28 “A Defence of Radbruch's Formula”, en Dyzenhaus, D. (ed.) Recrafting the Rule of Law: The Limits of Legal Order, Hart Publishing, Oxford / Portland, 1999, págs. 15-39, cita en pág. 17.

${ }^{29}$ Alexy, R. “El concepto y la validez del Derecho”, op. cit., pág. 53. 
de manifiesto en algunos fallos de los tribunales alemanes en relación con hechos acaecidos durante el período del régimen nacionalsocialista ${ }^{30} \mathrm{o}$ en la extinta República democrática alemana (RDA) ${ }^{31}$, que han negado el carácter jurídico de algunas leyes (promulgadas conforme a los procedimientos de creación de normas y obedecidas y aplicadas, esto es, válidas y eficaces) por razón de su contenido altamente injusto. Esto, sin embargo, no deja de ser la revisión de una situación histórica por parte de quienes detentan el poder tras el derrumbe de los sistemas políticos y jurídicos injustos: establece qué parte de todo aquello resulta ideológica y moralmente (in)asumible por el presente. Esta relevancia práctica a posteriori nada tiene que ver con el concepto de Derecho, sino con la ideología y la moral dominantes en el momento histórico. Son, por tanto, efectos contingentes. Aquí se trata, sin embargo, de buscar relaciones de causalidad entre la adopción de un concepto de Derecho y sus efectos. Alexy despliega en este sentido dos líneas de argumentación a favor de un concepto de Derecho no positivista: el argumento de la praxis jurídica y el efecto de riesgo.

Según el argumento de la praxis jurídica, si existe un consenso en la comunidad jurídica acerca de la necesidad de que las disposiciones estatales satisfagan determinados contenidos mínimos de justicia,

“se dispone ya de una argumentación jurídica enraizada en la praxis jurídica y no sólo de una argumentación moral para enfrentarse a los actos de un régimen injusto"32.

No escapa al propio Alexy la escasa resistencia que un consenso de este tipo ofrece frente a un régimen injusto, de manera que la efectividad del argumento de la praxis jurídica se referiría principalmente a regímenes injustos débiles en su fase inicial. Sea como fuere, este argumento está de más en relación con los sistemas jurídicos que ya incorporan en sus constituciones ciertos principios fundamentales de justicia; ¿qué aportaría un concepto de Derecho no positivista en un panorama como éste? ¿Acaso podría ofrecer una resistencia mayor que la que ya ofrece la propia Constitución? Parece

\footnotetext{
${ }^{30}$ Por ejemplo, la sentencia del Tribunal Constitucional alemán de 1968 en relación con el Decreto 11 que desarrollaba la Ley de Ciudadanía del Reich de 25 de noviembre de 1941, que privaba de la nacionalidad alemana por razón de la raza a los judíos emigrados (vid. Alexy, R. “A Defence of Radbruch’s Formula”, op. cit., págs. 18-19).

${ }^{31}$ Alexy se ha ocupado por extenso del asunto de los centinelas del muro de Berlín (Mauerschützen) en varios trabajos (Mauerschützen. Zum Verhältnis von Recht, Moral und Strafbarkeit, Vandenhoeck \& Ruprecht, Göttingen, 1993; Der Beschluß des Bundesverfassungsgerichts zu den Tötungen an der innerdeutschen Grenze von 24. Oktober 1996. Vandenhoeck \& Ruprecht, Göttingen, 1997 [de este último existe traducción castellana: "Derecho injusto, retroactividad y principio de legalidad penal. La doctrina del Tribunal Constitucional Federal alemán sobre los homicidios cometidos por los centinelas del muro de Berlín”, Doxa 23 (2000), pp. 197-232].

32 “El concepto y la validez del Derecho”, op. cit., pág. 55.
} 
que no. Al fin y al cabo, el argumento de la praxis jurídica incurre en el mismo error que el argumento de la indefensión: pensar que los argumentos jurídicos tienen, por sí mismos, una capacidad o efecto práctico de resistencia a la injusticia del que los argumentos morales carecen.

En todo caso, las consecuencias favorables de un concepto no positivista de Derecho se anticiparían en el tiempo también en el plano individual en lo que Alexy denomina el "efecto de riesgo": la adopción de un concepto no positivista del Derecho puede favorecer y/o acelerar el derrumbe de los sistemas injustos o, al menos, reducir el grado de injusticia porque las perspectivas de responder judicialmente ante un hipotético, pero, a la vez, seguro, derrumbe del sistema, desincentiva la participación en la injusticia, incluso de aquéllos que comparten sus fundamentos ${ }^{33}$. El argumento del efecto del riesgo será un buen argumento en la medida en que lo sea la predicción que contiene. Esta predicción tiene su fundamento en un cálculo de utilidad, o sea, en la prudencia de las personas, así como en otros factores, como la aversión al riesgo, la integridad moral, etcétera. Pues bien, de entrada, el efecto de riesgo resulta inocuo frente a los fanáticos, figura nada ajena a los sistemas de extrema injusticia, dicho sea de paso, que si algo no hacen, son cálculos de utilidad; al menos, en términos comprensibles para el sentido medio de la prudencia. Pero es que tampoco en relación con aquéllos que sí pueden verse potencialmente influidos por el "riesgo" de ser juzgados en el futuro resulta plausible el argumento. El participante en un sistema de extrema injusticia (por voluntad propia o por otro tipo de razones, por ejemplo, profesionales) se enfrenta a dos riesgos: de un lado, el riesgo a que se refiere Alexy, que es un riesgo incierto y a más o menos largo plazo, de ser juzgado como participante en un sistema de extrema injusticia tras el derrumbe de éste por los participantes en un sistema posterior; y, de otro lado, el riesgo, inmediato en el tiempo, de ser juzgado como opositor al régimen extremadamente injusto del que agente se niega a formar parte. A la proximidad en el tiempo hay que unir otra circunstancia: las garantías del proceso. Es probable que un sistema extremadamente injusto le suceda un sistema que incorpora ciertas garantías procesales, respete el principio de proporcionalidad de las penas y reconozca ciertos derechos en el cumplimiento de éstas. En cambio, ya sabemos cómo juzgan los sistemas totalitarios (procesos sumarios, por lo general, carentes de ningún tipo de garantías), precisamente para desincentivar la disidencia, la negación de obediencia o a aquéllos que, de un modo más o menos disimulado, se oponen al régimen. Pero es que también podría suceder que a un sistema extremadamente injusto siga otro sistema extremadamente injusto, como de hecho ocurrió tras la guerra en

${ }^{33}$ Idem, op. cit., pág. 56. 
Alemania oriental, donde el totalitarismo nacionalsocialista dio paso al totalitarismo pro-soviético. Desde un punto de vista estrictamente prudencial y no moral (que es de lo que se trata en este argumento del "efecto de riesgo”), ¿qué motivos puede tener un demócrata en estas circunstancias para, poniendo en riesgo su vida y la de los suyos, oponerse al sistema? Alexy no tiene en cuenta algunos factores, entre ellos la incertidumbre, que hacen bastante implausible el argumento de la efectividad ${ }^{34}$.

Hay un último aspecto problemático del argumento del "efecto de riesgo”. La efectividad de un concepto no positivista de derecho presupone, no sólo la asunción por los juristas de un tal concepto de Derecho, sino la percepción de la injusticia extrema e insoportable que ya no es Derecho y cuya obediencia o aplicación constituiría el principal cargo contra ellos en un futuro (y, por ahora, hipotético) juicio. Si no se es capaz de identificar la injusticia extrema e insoportable, resultaría irrelevante, desde el punto de vista de la efectividad, la adopción de un concepto no positivista de Derecho. La identificación del límite, dónde comienza el umbral de la injusticia insoportable, no es algo fácil. El propio Radbruch admite que "resulta complicado establecer la frontera entre los normas injustas, pero todavía jurídicas y las insoportablemente injustas"35; y no se avanza demasiado en claridad al afirmar, como hace Alexy, que el límite de lo soportable lo constituyen “exigencias morales mínimas”, como los derechos humanos elementales a la vida y a la integridad física ${ }^{36}$. Alexy pretende salvar la dificultad para establecer nítidamente un límite de lo soportable vinculando el aspecto material y el epistemológico de la corrección: "cuanto más extrema sea la injusticia, tanto más seguro su conocimiento”37, o lo que es lo mismo, que lo (más) insoportable resulta (más) evidente. Sin embargo, esta especie de intuicionismo moral al que recurre para establecer el límite de la injusticia extrema resulta criticable. El hecho de que no sólo no sea descartable, sino muy probable (tanto más probable cuanto más nos acerquemos al límite de lo soportable), la hipótesis de una pluralidad de percepciones de la evidencia, pone de manifiesto la carencia de un criterio objetivo de decisión. Percibimos como evidente, principalmente, aquello que hemos interiorizado en el proceso de socialización; así, la percepción de la injusticia extrema e intolerable, evidente al fin y al cabo, depende en su mayor parte, si no en toda, de las convicciones morales vigentes en la comu-

\footnotetext{
${ }^{34}$ Vid. Engländer, A. “Zur begrifflichen Möglichkeit der Rechtspositivismus. Eine Kritik des Richtigkeitsargument von Robert Alexy”, op. cit., pág. 458-459; Dorado Porras, J. Iusnaturalismo y Positivismo jurídico, op. cit., págs. 114-116.

${ }^{35}$ Radbruch, G. “Gesetzliches Unrecht und übergesetzliches Recht”, op. cit., pág. 89.

36 "El concepto y la validez del Derecho”, op. cit., pág. 54.

${ }^{37}$ Idem., pág. 57.
} 
nidad, lo que sitúa a la evidencia más como "una expresión de aceptabilidad en el sentido (...) de adhesión a una determinada forma de vida”, que como un signo de racionalidad u objetividad ${ }^{38}$.

\section{IV}

En este trabajo he intentado mostrar que tanto en el plano analítico, como en el plano normativo, cuando se trata de argumentos prácticos, el debate acerca del concepto de Derecho no está resuelto. A poco que se aborden con rigor las tesis positivistas y no positivistas, muchos de los argumentos esgrimidos a favor y en contra de los distintos conceptos de Derecho resultan implausibles, especialmente los argumentos de tipo práctico. Los efectos prácticos del Derecho dependen de las convicciones, evaluaciones y, sobre todo, de la integridad moral de aquellos que deben obedecerlo y aplicarlo. Pero en esta cuestión, bien poco relevante es cómo utilicemos el término “Derecho”. No es que un concepto de Derecho implique la evaluación moral del Derecho y haga depender de ella su validez y la existencia de un deber de obediencia al mismo (iusnaturalismo clásico) y otro concepto de Derecho imponga un deber de obediencia absoluto ignorando el contenido de las normas jurídicas (positivismo ideológico). La diferencia radica, como ha escrito Martín D. Farrell, en el momento en que esa evaluación se lleva a cabo: el no positivista sitúa la evaluación moral del Derecho al principio, antes de determinar cuándo una norma es una norma jurídica; el positivista, en cambio, lo hace al final, una vez identificado el Derecho, y lo hace porque, salvo en los casos de positivismo ideológico, está interesado en saber si existe una obligación moral de obedecer al Derecho ${ }^{39}$. Cuándo se tomen en consideración los juicios morales acerca del Derecho no determina de un modo definitivo, ni siquiera relevante, las acciones de los hombres si éstos no están dispuestos a seguirlos. Como otros muchos ${ }^{40}$, soy de la opinión de que la cuestión acerca del concepto de Derecho se resuelve en el plano de los intereses cognitivos o científicos y no en el de los argumentos morales.

${ }^{38}$ García Figueroa, A. Principios y positivismo jurídico, CEC, Madrid, 1998, pág. 379.

${ }^{39}$ Farrell, M. D. “¿Discusión entre el derecho natural y el positivismo jurídico?”, DOXA 21 (2001) Vol. II, págs. 121-128, cita en pág. 124.

${ }^{40}$ Entre los autores españoles, por ejemplo, Bayón, J. C. "El contenido mínimo del positivismo jurídico”, op. cit.; Navarro, P. E. “Tensiones conceptuales en el positivismo jurídico”, op. cit.; Dorado Porras, J. Iusnaturalismo y Positivismo jurídico, op. cit. o Escudero Alday, R. Los calificativos del positivismo jurídico, Civitas, 2004.

\section{DOXA 28 (2005)}

